\title{
IMPLEMENTING EXPERIENTIAL EDUCATION ON ENGINEERING AND SOCIETY
}

\author{
Matthew Harsh, Brandiff Caron, Deborah Dysart-Gale, Govind Gopakumar, and Ketra Schmitt \\ Centre for Engineering in Society, Concordia University, Montreal, QC, Canada \\ Matthew.Harsh@Concordia.Ca
}

\begin{abstract}
Recent educational research in engineering has examined the challenges Canadian universities are facing when implementing graduate attributes, especially those attributes that involve significant social components (such as ethics and equity, impact of technology on society, and communication skills). In response to these challenges, this paper asks: how might experiential education be used as an approach to teach non-technical graduate attributes? Having asked this question at our own institution, we are in the process of implementing experienced-based approaches to engineering education. We describe our efforts in curricular and non-curricular spaces which include adding project-based components to our existing courses on technology and society and communication, designing a new experiential course on creativity and innovation, serving as clients for capstone courses, facilitating reflection for our co-op program, developing a workshop on community engagement, and organizing design competitions in our innovation centre. We analyze the challenges and the benefits of these approaches. Our argument is that experience alone may not lead to planned learning outcomes, so finding creative ways to promote reflection on experience becomes critical. In our programs, this has meant: playing the role of both client and facilitator in projects; partnering with faculty members in other disciplines; and having students directly interact with users from very different backgrounds. Through these approaches, we are finding ways to help students visualize the lived context of technology use in communities, and ways to help them understand the non-technical components of design and co-op work that are essential if we want to create just and sustainable outcomes though technology. The implication of this preliminary reflexive account is that experiential education holds much promise for improving instruction related to non-technical graduate attributes.
\end{abstract}

Keywords: experiential education; engineering and society; graduate attributes

\section{INTRODUCTION}

CEEA15; Paper 001

McMaster University; May 31 - June 3, 2015
The establishment of the CEAB graduate attributes assessment as a method for accreditation of engineering programs is the major force shaping the focus of engineering education [1]. Much activity is dedicated to determining how to assess student learning under this new accreditation regime $[2,3]$. However, the long-term shape of CEAB assessment and its ultimate impact on Canadian engineering education is still unknown. What is known is that $\mathrm{CEAB}$ has as its fundamental goals (a) ensuring that educational programs meet basic standards and (b) assuring the continual improvement in the quality of engineering education programs in Canada [4].

The mandate to improve the quality of engineering education arguably opens the possibility for making wideranging changes to the way engineers are educated in Canada. Reflecting growing public awareness of the technogenic character of many environmental and social problems, the new assessment measures can be a tool to educate young engineers who link disciplinary competence with awareness of the social and environmental implications of professional practice.

The need to foster this new type of practitioner has given rise to new types of pedagogical structures [5]. One such pedagogical structure references the renewed interest in experiential education [6]. While experiential learning is widely accepted as a way to improve learning, our experience suggests that simply, students must be supported when applying their engineering knowledge base with stakeholders from different cultural and economic backgrounds, often under conditions of ethical ambiguity. Negotiating this terrain requires students to develop the ability and willingness to reflect upon all aspects of their professional practice.

This paper will describe the role of the Centre for Engineering in Society (CES), as a provider of complementary engineering education, in facilitating experiential education. It will outline a variety of educational interventions that integrate technical and nontechnical aspects of engineering training within the context of the CEAB graduate attributes. 


\section{EXPERIENTIAL EDUCATION IN THE CENTRE FOR ENGINEERING IN SOCIETY}

\subsection{Centre for Engineering in Society}

The Centre for Engineering in Society (CES) is an academic group within the Faculty of Engineering and Computer Science, whose research and teaching expertise focus on non-technical areas of engineering. Faculty members come from Technical Communication, Science and Technology Studies, and Risk Assessment [7]. In its present form, CES has only existed since 2011, although its institutional predecessors were charged with teaching courses in the social aspects of engineering since the 1970s. This fact speaks first to the persistence of the idea that engineers needed to consider societal aspects of their practice. It also signals an emerging conviction that engineering educators must offer students more than coursework to engage them with social context of their practice.

CES sees as its mandate the extension of student engagement beyond coursework and into more meaningful applications such as experiential learning. While experiential learning has been introduced in other areas of the engineering programs (e.g., co-op programs and extracurricular engineering project clubs), CES, with its curricular focus on social, ethical and communityoriented practice, has foregrounded the non-technical graduate attributes in its experiential learning activities.

\subsection{International Immersion Experience}

CES has a close relationship with the university's twoyear-old District 3 Centre for Entrepreneurship and Innovation. An extracurricular site where students can develop social entrepreneurial and business ideas, District 3 emphasizes design principles focused not on product and technology, but on user needs, demanding that teams continuously engage stakeholders through interviews and direct observations. One effective method for fostering user-centered innovative design is through so-called "design challenges", in which teams are formed and compete by rapidly prototyping solutions to the challenge problem. The winning team is then given a cash incentive to further iterate the prototype under the supervision of District 3 coaches.

One of the authors, Dr. Govind Gopakumar, organized a design challenge in Fall 2014 in the context of an ongoing research partnership with the Bangalore Bus Commuter Forum (BBPV) - a citizens platform that works with different stakeholders in order to imagine and advocate for inclusive and affordable public transport in the metropolitan city of Bangalore, India. The objective of the design challenge was for interdisciplinary student groups at Concordia University to become familiar with the challenges of public transportation in Bangalore city, and then propose designs for inclusive and affordable buses in the city of Bangalore, India. While still a novel venture, this design challenge benefited from and extended its reach and potential by parallelly leveraging two initiatives that Dr. Gopakumar was involved in at that time. First, Dr. Gopakumar had received a partnership grant from the Shastri Indo-Canadian Institute to work with a Bangalore-based performance artist and the BBPV to design a multi-media manifesto for inclusive buses in Bangalore. Second, CES received support from private donors to establish a Global Engineering Initiative fund to support international and community-oriented engineering practice.

A key challenge that student groups faced in proceeding with the design challenge was an inability to visualize the lived context of buses in Bangalore. Many students had never visited India and so were unfamiliar with what might be an appropriate design for that context. This challenge was partially overcome with the help and assistance provided by BBPV members by the way of documents, comments, and insight. This sharing was facilitated by utilizing a tumblr website as a virtual repository for design-related information and as a platform for information exchange between student teams as well as 'clients' based in Bangalore.

Another means of reducing the unfamiliarity with context was by sharing video footage that Dr. Gopakumar had accumulated of bus travel in Bangalore (in the process of producing a short documentary on the social aspects of bus commuting) with student teams. Through these measures, students could begin to relate to the texture of the context they wanted to design in. A key benefit was the ability to relate their design knowledge to a complex societal context. Working with the forum members (a relevant stakeholder) provided them with an ability to target their designs better.

At the conclusion of the design challenge, five designs produced by student teams were evaluated by a jury composed of an urban anthropologist and performance artist based in Bangalore. Through this evaluation a single team was chosen that successfully incorporated the challenges facing inclusivity and affordability. This student team was able to travel to Bangalore in December 2014 to present their design to a wider public audience as part of a bus festival organized by BBPV. These experiences provided the students with a rich opportunity to engage many of the graduate attributes, in particular communication skills and team work, in addition to an awareness of issues of equity and social impact of technology. We are also optimistic that the confidence this experience has given these students will provide skills for lifelong learning.

\subsection{Community Engagement Workshop for Engineers}


In collaboration with colleagues from several universities in the USA and South Africa, Dr, Matthew Harsh designed and implemented a workshop on community engagement for engineering graduate students. We were motivated by a gap in engineering education that we observed in our own teaching and in our research on innovation policy and inequality. We noted that engineering students (in both developed and developing countries) were increasingly engaging with local communities to carry out research and technological development projects, yet these students rarely receive any training on community engagement or development as part of their engineering programs. Acknowledging that engineering curricula are already jam-packed with technical courses, we asked ourselves: Can we address the 'community gap' in engineering education through an intensive workshop format?

Across three countries and two continents, we conducted several iterations of a short course on community engagement, each with about 15-20 participants. The 16-hour course introduces engineering graduate students to the complexities and challenges of community engagement and development through an experiential and hands-on approach. The program goals are for participants to be better able to: (a) look beyond technology to see how people, values, and other factors influence and are embedded in technologies; (b) listen to and learn from people about these non-technical aspects; (c) empower communities through a greater understanding of how technology relates to decisionmaking, managing, planning, and resource use in community and practitioner interactions.

Community Engagement Workshop (CEW) activities are designed to help participants systematically consider the societal dimensions of engineered systems and develop a toolkit of questions and methods for engaging with stakeholders. After two pilot deployments in Atlanta, Georgia, USA, and Cape Town, South Africa, we ran two CEWs in 2014, one in at Concordia University in Montreal, Canada, one in Arizona State University, Tempe, USA. We run a total of 12 activities, ranging from group discussions to role-play to card games to casestudy reviews, during the workshop. In addition, three non-facilitator faculty partners (ranging from engineering and sciences to social sciences) who have experience working with communities are invited to share their work and provide examples of community engaged research and practice. The culmination of the workshop is a group project where participants design a pilot community engagement project and present it to a panel of faculty members and members of community organizations.

Implementing this approach involved several challenges including designing mutually beneficial collaborations with both technical colleagues and community partners, and trying to provide experiences which introduce both the intellectual and emotional challenges involved in working in communities that can seem very foreign, even if they are close to the university where students have been studying. Our approach was to layer interactive activities with individual and group reflection. We relied on structured facilitated discussions after engaging with a visiting faculty member or community member and at several stages in the group project, but we also strategically utilized informal discussions over coffee and lunch breaks where participants, facilitators and community or faculty guests learned from each other.

We are in the process of analyzing quantitative and qualitative data based on pre and post student surveys and concept mapping instruments. Preliminary results indicate that after completing the workshop, students have a greater understanding of how social systems and technological systems interact to create positive impacts in communities, and a greater appreciation of key aspects of communication in community engagement, particularly the importance of communal problem framing and how to overcome listening biases.

\subsection{Bringing the Real World to the Classroom}

Dr. Gopakumar organized an opportunity for interaction with real world clients and stakeholders far outside the students' usual area of experience, while Dr. Harsh created experiences outside the curriculum. However, similar challenges can be integrated within the curriculum. Another author, Dr. Brandiff Caron, added experiential value to a Computer Science project course by acting in the role of a real world client. In these courses students work in teams to complete a functioning website that meets the client's requirements. His requirement was to establish a web presence for a deliberative democracy project.

Dr. Caron served as client to 6 teams of 9 students, each addressing a sub-task of the project. Team members integrated their knowledge of coding languages, the agile and UI development processes, and user testing methods. However, the client's requirements demanded that students also address issues facing the intended users of the platform, such as low literacy and unfamiliarity with technology use. These would impede the goal of creating a working website where users can listen to and/or record viewpoints on several pressing social issues. Throughout the semester and during class presentations, Dr. Caron acted as a client, making requests about user-interfaces, website design, usability, etc. The students would then work in teams to implement those requests. For many students, this was the first experience working with an actual client.

To enable students to consciously connect their experience to the non-technical graduate attributes, a reflective component was added. Dr. Caron opened up 
office hours during which the students were encouraged to break the client/student team wall and reflect on the challenges faced. He would, at this point, take off my "client" hat and don my "professor's hat and guide them through reflective learning exercises. In this way, we aimed at bridging the university and work place divide while optimizing the reflective learning components that the university is positioned to provide.

\subsection{Experiential Innovation in the Curriculum}

Given the constraints of the prescribed engineering curriculum, and a pedagogical culture that emphasizes the need for explicit instruction in propositional knowledge, quantitative methods, etc., it is often quite difficult to advocate for enhanced experiential learning opportunities. Providing such experiential opportunities becomes easier when they can be integrated into existing curriculum. Some examples follow.

2.5.1 Technical Communication. CES is responsible for technical communication courses. We have devised a number of ways to incentivize students to utilize the final proposal project, "a substantial writing assignment that asks students to prepare a formal proposal for solving some particular technical problem within their chosen major that includes a detailed technical description of the problem they aim to solve and a suggestion for how to solve that problem," as an experiential learning opportunity. A number of avenues have been created to permit students to make serious attempts to obtain funding for viable proposals that can be pursued after the end of the semester. Teaming up with District 3 Centre for Entrepreneurship and Innovation and introducing students to a number of undergraduate grant opportunities, we are able to directly link students with real-world funding opportunities.

This innovation was met with a pleasantly surprising success. Almost a quarter of the students seek out the instructor to discuss, not just how to achieve a good grade on the assignment, but how to have the best chances of successfully receiving funding. This is the kind of realworld writing experience that engineers need to have. Having students in the required technical communication course working on these real-world funding opportunities in an environment with a knowledgeable professor and mentor is, again, a great place to bridge the university and the working world though reflective learning.

2.5.2 Social Impact of Technology. Over the past three years, we have taught required courses on technology and society ('Impact of Technology on Society' and 'Social and Ethical Dimensions of Information and Communication Technologies') via a project-based experiential approach. A main goal of these courses is to help engineering students understand and participate in technology assessment: learning how to assess the social and ethical issues connected to new technologies, engage with stakeholders about these issues, and re-configure socio-technical systems to create more sustainable and just outcomes. Students learn about technology assessment by doing it. The centerpiece of the course is a group project in which students conduct a technology assessment on an emerging area of engineering or technology. They probe social and ethical issues via research, design and implement creative engagements to discuss and debate issues with fellow students participating as stakeholders and users, and prepare a detailed report where they present realistic changes to social and technical components of their case study to create equitable processes and outcomes. The approach thus integrates several graduate attributes: impact of technology on society, ethics and equity, communication and professionalism.

\subsection{Elective Courses within the Curriculum}

The tightly packed engineering curriculum offers few elective courses that in other disciplines frequent serve as opportunities for experiential learning. This situation is exacerbated in the province of Québec, where students typically pass through the college system before entering university, leaving engineering students with only one elective course remaining in their program. In principle, we feel it is desirable for engineering students to take this single elective outside their schools of engineering for the experience of interacting with non-engineers, and for that reason have not directly developed electives at the undergraduate level. Nevertheless, we have designed elective courses for graduate students, in which seats are provided for undergraduates.

Over the past two years, we have developed one such elective course in innovation, creativity and critical thinking. This course is organized along the principles of design thinking, in which students address "a real problem experienced by real people". Students typically must be guided past an initial preference to design products that they find technically compelling and thus "sure to work", and focus their attention instead on identifying and interviewing a target group of individuals to determine what sort of problems are of concern, not to the students, but to their informants themselves. This brings students into intensive and repeated contact with groups with whom they might not normally interact.

To best foster meaningful interactions, we encourage teams to "go with what you know". When designing the course, we initially anticipated that teams would design solutions to problems faced by working groups within their own disciplines (e.g., laboratory measuring devices or research tools), as this would provide the easiest route to identifying users to interview, as well as viable 
products. However, in our experience, student teams show a marked preference for working with groups over wide social distances, with homelessness and addiction favored topics. These cases provide excellent instructional opportunities in professional communication ethics, as students come to realize that their skill set does not allow them to authentically interact with homeless or substance abusers themselves, but rather with first responders, social workers and others with the training for direct and sustained interaction with the homeless or addicted (as expressed by one student, "we help the helpers").

In collaboration with the District 3 Centre and with a growing number of community partners, the course has generated several ongoing projects, in which engineering students provide shelters with software tools and building solutions for their work. The fact that these projects require more than a single semester to achieve impact requires students to engage with the graduate attributes of professionalism and project management, to make appropriate and realistic statements to the stakeholders about the continuation of the project after the end of the semester, and to formulate and execute viable plans for continuity.

\subsection{Reflective Learning}

Centre faculty members also help lead the reflective learning seminar that is required for all students in the university's co-operative work-study placement semester. The reflective learning seminar is a major component of the co-op program's mission to "bridge university life and the working world" (from co-op website). Experiential learning is explicitly recognized in Concordia's co-op program as the pedagogy of choice. Through leading group discussion and prompting students to share their experiences, the reflective learning component of the student's co-op work term is the primary place where students are guided in framing their work placements as educational environments. One of the things that is brought to the foreground during these reflective learning seminars is the fact that "experience" alone may not always lead to "learning" (of the sort professors would like to see). Hence, if we are genuinely interested in "experiential learning," the importance of reflecting on the experience co-op work terms provide cannot be overstated.

\section{CONCLUSION}

The introduction of the CEAB graduate attributes has occasioned reflection about the direction of engineering education, and in the best case scenario, offers the opportunity to change our practices for the better. At CES, we have integrated the non-technical attributes into a variety of experiential learning.
While such experiences require logistical planning and organization of community partners, our experience suggests that instructors must also be available to help students actively reflect on their experience by reflecting on the graduate attributes they are acquiring: especially teamwork, social awareness, and professionalism

\section{Acknowledgements}

We wish to acknowledge our partners at the District 3 Centre for Entrepreneurship and Innovation as well as our generous private donors who provide funding necessary for prototyping and promoting course projects to realize real potential beyond the classroom. We also acknowledge our community partners, who willingly give of their time to provide access for students. Thanks also to the reviewers of this paper and abstract.

\section{References}

[1] Brian Frank, "Development and process criteria for CEAB graduate attribute assessment," in Proc. Canadian Engineering Education Assoc., 2011. Available as of April 20, 2015 from

http://queens.scholarsportal.info/ojs/index.php/PCEEA/articl e/view/3682

[2] Guy Cloutier, Ronald Hugo, and Rick Sellens, "Mapping the relationship between the CDIO syllabus and the 2008 CEAB graduate attribues," in Proc. $6^{\text {th }}$ International CDIO Conference, 2010. Available as of April 20, 2015 from $\mathrm{http} / /$ scholar.google.com/scholar?hl=en\& $\mathrm{q}=\mathrm{CEAB}+$ graduat $\mathrm{e}+$ attributes\&btnG $=\&$ as_sdt $=1 \% 2 \mathrm{C} 33 \&$ as_sdtp $=$

[3] Said Easa, Marc Rose, and Robert Beaumont, "Innovative assessment of CEAB graduate attributes in a large class: Law and ethics in engineering practice." Proc. Canadian Engineering Education Assoc., 2012. Available as of April 20, 2015 from

http://queens.scholarsportal.info/ojs/index.php/PCEEA/articl e/view/4680

[4] Jessica Harris, Alan Steele, and Donald Russell, "Progress on defining the CEAB graduate attributes at Carleton University," in Proc. Canadian Engineering Education Assoc., 2011. Available as of April 20, 2015 from http://library.queensu.ca/ojs/index.php/PCEEA/article/view/ 3628

[5] Brandiff Caron, Govind Gopakumar, Deborah Dysart-Gale, and Matthew Harsh, "Navigating a constitutional moment: Reflections on implementing graduate attributes in Canadian engineering education," Engineering Studies, vol. 56, no. 1, pp. 44-61, 2014. Available as of April 20, 2015 from http://www.tandfonline.com/doi/abs/10.1080/19378629.201 4.905790\#.VTUWWGbneLI

[6] Amy Shellman, "Empowerment and experiential education: A state of knowledge paper," Journal of Experiential Education, vol. 37, no. 1, pp. 18-30, 2014. 
[7] Govind Gopakumar, Deborah Dysart-Gale, Brandiff Caron, and Robin Drew, " Models for leadership in curricular innovation: Concordia's Centre for Engineering in Society," in Proc. Canadian Engineering Education Assoc., 2012. Available as of April 20, 2015 from http://library.queensu.ca/ojs/index.php/PCEEA/article/view/ 4660 